\title{
VIVENCIANDO O COTIDIANO DO CUIDADO NA PERCEPÇÃO DE ENFERMEIRAS ONCOLÓGICAS ${ }^{1}$ \\ LIVING FULLY THE DAILY LIFE OF CARE IN THE VIEW OF ONCOLOGICAL NURSES VIVIENDO EL COTIDIANO DEL CUIDADO EN LA PERCEPCIÓN DE ENFERMERAS ONCOLÓGICAS
}

\author{
Cinthia Aquino Gargiulo², Maria Carmen Simões Cardoso de Melo 3 , Anna Maria de Oliveira Salimena ${ }^{4}$. Vânia Maria \\ Freitas Bara ${ }^{5}$ Ívis Emilia de Oliveira Soura ${ }^{6}$
}

\footnotetext{
${ }^{1}$ Recorte da Pesquisa realizada como Trabalho de Conclusão do Curso de Graduação em Enfermagem "O Processo do Cuidar na Enfermagem Oncológica".

2 Enfermeira pela Universidade Federal de Juiz de Fora (UFJF). Minas Gerais, Brasil.

${ }^{3}$ Orientadora da Pesquisa. Mestre em Enfermagem. Professora Assistente do Departamento Enfermagem Aplicada da Faculdade de Enfermagem FACENF/UFJF. Doutoranda do Programa de Pós-Graduação da Escola de Enfermagem Anna Nery (EEAN) da Universidade Federal do Rio de Janeiro (UFRJ). Pesquisadora Grupo de Pesquisa "O cotidiano do cuidar em Enfermagem" da FACENF/UFJF. Pesquisadora do Núcleo de Pesquisa em Enfermagem em Saúde da Mulher (NUPESM) da EEAN/UFRJ. Minas Gerais, Brasil.

${ }^{4}$ Mestre em Enfermagem. Professora do Departamento Enfermagem Aplicada da FACENF/UFJF. Doutoranda do Programa de Pós-Graduação da EEAN/UFRJ. Pesquisadora do Grupo de Pesquisa "O cotidiano do cuidar em Enfermagem" da FACENF/ UFJF. Pesquisadora do NUPESM/EEAN/UFRJ. Minas Gerais, Brasil.

${ }^{5}$ Mestre em Enfermagem. Professora do Departamento Enfermagem Aplicada da FACENF/UFJF. Pesquisadora do Grupo de Pesquisa "O cotidiano do cuidar em Enfermagem" da FACENF/UFJF. Minas Gerais, Brasil.

${ }^{6}$ Doutora em Enfermagem. Professora Titular de Enfermagem Obstétrica do Departamento Enfermagem Materno-Infantil da EEAN/UFRJ. Pesquisadora e Membro da Diretoria do NUPESM/EEAN/UFRJ. Rio de Janeiro, Brasil.
}

PALAVRAS-CHAVE: Enfermagem oncológica. Cuidados de enfermagem. Processos de enfermagem.

RESUMO: Este estudo teve como objetivo analisar a percepção das enfermeiras sobre o significado do processo do cuidar dispensado ao paciente portador de câncer. Utilizou-se a abordagem qualitativa visando a busca da essência, particularidades e singularidades, sendo entrevistadas dez enfermeiras de duas instituições, da cidade de Juiz de Fora, atuantes no diagnóstico e tratamento do câncer. A captação de dados se deu a partir de roteiro semi-estruturado permitindo livres manifestações acerca do tema, gravadas em fita cassete. A análise compreensiva das entrevistas demonstrou a presença de um cuidar holístico e humanizado, o sofrimento e a sensação de impotência das enfermeiras diante da morte, a presença da fé como suporte de seu agir e o interesse em atualizar-se cientificamente e tecnologicamente, porém aponta inconsistências na implementação da Sistematização da Assistência de Enfermagem como estratégia do cuidar. Evidenciam-se vivências do cotidiano profissional perpassadas por características essencialmente femininas na relação estabelecida com a clientela.

KEYWORDS: Oncologic nursing. Nursing care. Nursing process.

\begin{abstract}
The objective of this study is to analyze nurses' perceptions about the meaning of the care process offered to cancer patients. Using a qualitative approach, ten nurses who work with the diagnosis and treatment of cancer from two institutions in the city of Juiz De For were interviewed, seeking the essence, particularities, and singularities of this process. The data was collected using a questionnaire with semi-structured questions, which permitted open manifestations from the interviewees in their responses, recorded on audio cassette. The comprehensive analysis of the interviews demonstrated the presence of a holistic and humanized care process, suffering, a sensation of impotence from the nurses in the face of the death, the presence of the faith as support for their actions, and an interest in scientifically and technologically updating the care process. However, it points out inconsistencies in the implementation of the Systematization of Nursing Care as a care strategy. This study evidences daily life in the care process laden with essentially feminine characteristics in the relationships established with the clientele.
\end{abstract}

Anna Maria de Oliveira Salimena

Endereço: R. Marechal Cordeiro de Faria, 172

36.081.330 - Carlos Chagas, Juiz de Fora, MG, Brasil.

E-mail : annasalimena@terra.com.br
Artigo original: Pesquisa

Recebido em: 16 de abril de 2007 Aprovação final: 28 de setembro de 2007 
PALABRAS CLAVE: Enfermería oncológica. Atención de enfermería. Procesos de enfermería.
RESUMEN: El objetivo de este estudio es el de analizar la percepción de las enfermeras sobre el significado del proceso del acto de cuidar al paciente con cáncer. Para la investigación se utilizó el abordaje cualitativo, buscando la esencia, las particularidades y singularidades del proceso. Fueron entrevistadas diez enfermeras de dos instituciones de la cuidad de Juiz de Fora, que actúan en el diagnóstico y en el tratamiento del cáncer. La recolección de los datos se efectuó a partir de un guión parcialmente estructurado permitiendo libres manifestaciones acerca del tema, las cuales fueron grabadas en una cinta casete. El análisis comprensivo de las entrevistas demostró la presencia de un cuidar integral y humanizado del equipo, el sufrimiento y la sensación de impotencia de las enfermeras ante la muerte, la presencia de la fe como soporte de sus acciones y el interés en actualizarse científicamente y tecnológicamente. Las entrevistas señalan, sin embargo, inconsistencias en la implementación de la Sistematización de la Asistencia de Enfermería como estrategia del acto de cuidar. También se evidencian vivencias del cotidiano profesional marcadas por características esencialmente femeninas.

\section{INTRODUÇÃO}

Durante a formação acadêmica várias são as oportunidades de se deparar com disciplinas, que dentre seus vários conteúdos, abordam também o câncer. $\mathrm{O}$ assunto que anteriormente já despertava interesse motivou o desenvolvimento de estudos que proporcionassem maior conhecimento sobre o tema, principalmente sobre a promoção da saúde, a detecção precoce, o controle e o tratamento da doença.

Neste sentido realizei estágio curricular e extracurricular em instituições especializadas no diagnóstico e terapêutica oncológica, nas unidades de internação: clínicas, cirúrgicas e de terapia intensiva. No desenrolar destas atividades de formação e enriquecimento profissional, observando o trabalho das enfermeiras, a relação delas com outros profissionais da área da saúde, e com os pacientes, me senti instigada a conhecer melhor a realidade deste processo do cuidar, a partir dos depoimentos destas profissionais, sobre sua prática. A esta inquietude, soma-se o aspecto de serem elas mulheres, atuando em seu cotidiano profissional na assistência a uma clientela portadora de uma doença que, por si só, mobiliza as mais variadas emoções e sentimentos.

Ainda hoje os pacientes oncológicos iniciam o tratamento em fase adiantada do câncer, o que implica muitas vezes, em comprometimentos os mais diversos, nos aspectos físicos, emocionais e sociais. Além daqueles motivados pela própria patologia, ainda existem os que se instalam pela terapêutica, muitas vezes mutiladora e/ou agressiva, por seus efeitos adversos. E devido ao estado clínico ou pelo próprio tratamento, esses pacientes precisam se afastar por longos períodos, do convívio familiar, social e profissional. Face ao exposto, as demandas desta clientela são múltiplas e várias, sendo necessário para atendê-las, um planejamento que as contemple em toda a sua abrangência.
A Sistematização das Ações de Enfermagem (SAE), valendo-se de todos os passos do processo, vem permitindo aos enfermeiros um cuidar científico e humanizado destinado a uma assistência qualitativamente adequada. Este assume dimensão especial quando direcionado ao paciente oncológico no estabelecimento ético das prioridades, onde se deve considerar a individualidade, singularidade, estilo de vida, crenças e valores culturais. ${ }^{1}$

$\mathrm{O}$ agir da enfermeira tem sua origem no cuidado direcionado à clientela, tendo como meta a melhoria e a qualidade de vida da pessoa. Esta afirmativa encontra ressonância ao ser apontado: "quando os enfermeiros conseguirem mostrar às pessoas com câncer que é possível viver tendo câncer, suprindo as suas necessidades de vida, dentro do seu potencial, eles conseguiram cuidar de fato, com real valor da palavra". $2: 51$

O cuidar é a base do processo de atuação da enfermeira e, para esta ser bem sucedida, é necessário que identifique as necessidades de seu cliente e família e as formas de sua resolução, numa perspectiva de atuação holística e humanizada. Assim, no desenvolvimento de suas atividades, as profissionais devem estar preparadas para prestar atendimento tanto nos comprometimentos emocionais, psicológicos e sociais, quanto para auxiliar na adaptação de limitações decorrentes da evolução e/ou tratamento da doença, sendo então imprescindível o adequado preparo da equipe de enfermagem para as demandas do cuidar dessa clientela. ${ }^{3}$

Tradicionalmente a enfermagem é exercida majoritariamente por profissionais do sexo feminino e no contexto da enfermagem oncológica não é diferente. Buscou-se, então, dar voz às profissionais que têm como objeto de seu cotidiano profissional o cuidado ao paciente portador de câncer, diante das indagações que motivaram a escolha do tema para estudo, delineando-se a seguinte questão norteadora: 
como as mulheres enfermeiras de oncologia percebem sua prática do cuidar?

$\mathrm{Na}$ busca de respostas a tais questionamentos, foi estabelecido como objetivo do estudo: analisar a percepção das enfermeiras sobre o significado do processo do cuidar dispensado ao paciente portador de câncer.

\section{METODOLOGIA}

No desenrolar das reflexões sobre o enfoque que se pretende dar ao estudo, a abordagem qualitativa se mostrou adequada, por trazer em si a possibilidade de investigação tanto de aspectos objetivos quanto também daqueles particulares e subjetivos. Nesta perspectiva de visualização pode ser encontrada fundamentação em Minayo ao destacar: "a pesquisa qualitativa responde a questões muito particulares. Ela se preocupa, nas ciências sociais, com um nível de realidade que não pode ser quantificado. Ou seja, ela trabalha com o universo de significados, motivos, aspirações, crenças, valores e atitudes". 4:21

A realização do estudo foi pautada nas orientações das normas legais que respaldam a pesquisa envolvendo seres humanos, ${ }^{5}$ como o estabelecido na Resolução No 196/96, tendo sido o seu projeto encaminhado e aprovado pelo Comitê de Ética em Pesquisa da Universidade Federal de Juiz de Fora (UFJF), em Minas Gerais, conforme protocolo No 804.110.2006.

Foi também obtida a aprovação da direção das duas instituições especializadas na assistência a pacientes oncológicos, que foram cenários eleitos para o estudo, ambas situadas em Juiz de Fora, na Zona da Mata Mineira. Estes hospitais escolhidos fazem atendimentos tanto pelo Sistema Único de Saúde (SUS), quanto particular, através de planos de saúde, sendo, uma dessas instituições, de cunho filantrópico.

A assistência é desenvolvida em nível ambulatorial e de internação a clientes não somente de Juiz de Fora, mas também de vários outros municípios da região. Suas atividades se desenvolvem no diagnóstico, tratamento e controle do câncer, através da disponibilização de profissionais capacitados para a realização de cirurgias, exames, quimioterapia e radioterapia.

A obtenção das informações se deu nos meses de julho e agosto do ano de 2006. Não foram depoentes todas as enfermeiras das duas instituições, por ter se usado como critério limite o ponto de saturação dos dados. Após a anuência consciente e voluntária cada participante assinou o Termo de Consentimento Livre e Esclarecido.

Os depoimentos foram coletados através de entrevistas gravadas em fita cassete, realizadas com dez enfermeiras que atuam a pelo menos um ano na instituição, respondendo às indagações: - o que significa para você o processo do cuidar na enfermagem oncológica? - que estratégias você tem utilizado para sua atuação no cotidiano profissional junto a essa clientela? Estas indagações foram elaboradas de forma aberta, com a finalidade de permitir a livre manifestação das participantes. Também se lançou mão de anotações no diário de campo referentes às expressões não verbais. As depoentes foram identificadas com nomes de cores, de forma a garantir o anonimato, conforme assegurado anteriormente. Após a transcrição dos depoimentos os significados foram destacados e separados, sendo realizada a análise compreensiva dos mesmos conforme preconizado. ${ }^{6}$ Desta organização emergiram as seguintes unidades de significação: - significados do cuidar: a dimensão emocional, a terminalidade e a fé; - a sistematização da assistência: uma estratégia de aplicação do conhecimento no cotidiano do cuidar.

\section{ANÁLISE DOS DEPOIMENTOS}

\section{Significados do cuidar: a dimensão emocional, a terminalidade e a fé}

O cuidado é um sentimento inerente ao ser humano, que percorre toda humanidade e está presente em nossa vivência diária, na família, no trabalho, no convívio social, fortalecendo sentimentos e conservando a relação entre quem cuida e quem é cuidado. "O cuidado é aquela condição prévia que permite o eclodir da inteligência e da amorosidade, o orientador antecipado de todo o comportamento para que seja livre e responsável, enfim tipicamente humano". 7:22

A enfermagem é a ciência e a arte de cuidar dos seres humanos em suas necessidades humanas básicas, devendo o cuidar/cuidado ser uma experiência vivida por meio de uma inter-relação pessoa com pessoa, lembrando que tão importante quanto o cuidar, é estarmos atentos aos efeitos que o cuidado produz nos pacientes. “Ter pensamentos e atitudes que demonstrem cuidados como ser atenciosa, gentil, preservar a dignidade do paciente, expressar-se com empatia, ser paciente, estar emocionalmente presente, reconhecer a humanidade do outro, fazer ao outro o que gostaria que fosse feito a si mesmo, 
e ser expert nas suas ações profissionais são algumas das ações de cuidado da enfermeira". 8:77 As dimensões deste cuidado apontam abrangência e envolvimento. Pode ser observado na assertiva de um dos depoimentos, que se evidencia, quando assim se expressa: [...] a gente vive aqui dentro assim, como amigo, como família, então o sofrimento da gente vai de acordo com isso, a gente vai sofrendo, mas a gente sabe que tem mais pra gente cuidar, a gente vai sofrer mais com aqueles outros e a gente vai se envolvendo nisso assim, dessa forma, mas é, gostando cada vez mais, cada vez mais deles, cuidando mais, com muito carinho ( $E$ azul).

O cuidar é de grande importância quando dispensado ao cliente e torna-se mais relevante ainda, quando é direcionado a pessoas com neoplasias malignas. Percebe-se que as enfermeiras que assistem esses pacientes têm o desafio de encontrar significados e respostas aos questionamentos do processo de viver - adoecer, curar, morrer - e de implementar medidas para promover a vida ou aliviar o sofrimento.

O cuidado, essência da enfermagem, volta-se para a busca da qualidade de vida e para a compreensão do ser humano como um todo. É preciso estar sempre atento para que se possa conhecer, saber o que o outro necessita e como ajudá-lo nesse processo. Vislumbra-se essa visão na referência de uma das entrevistadas: [...] a essência, da enfermeira, da enfermagem é o cuidar, não importa se for na oncologia, se for, o que for, a especialidade que for, o mais importante para nós, pra mim, na enfermagem é o cuidar (E azul).

O processo do cuidar envolve relacionamento interpessoal originado no sentimento de ajuda e confiança mútuas. ${ }^{9}$ Logo, cuidar é servir, é perceber o outro em pequenos gestos, em pequenas falas, em suas limitações, é uma palavra de carinho e, para realizar esse cuidar, é preciso que os profissionais tenham afinidade e afetividade em relação aos clientes, principalmente no caso dos portadores de câncer.

A humanização na prática da enfermagem tem como essência a comunicação enfermeiro-doente-família, pois é através dela que se estabelece a relação entre os seres humanos, sendo o meio de informação aos pacientes e familiares e o recurso terapêutico de enfermagem. A humanização propõe mudanças no ambiente de trabalho, familiar e no interior do ser humano, atingindo, o coletivo. Atuar humanamente e cuidar do ser doente contribui para que os obstáculos profissionais sejam mais brandos. ${ }^{10}$

$\mathrm{Na}$ assistência ao cliente com câncer, o processo de humanização no cotidiano do cuidar, parece se estabelecer de forma muito mais evidenciada. Tal possibilidade pode se originar tanto pela própria doença, sofrimentos e terapêutica, dela decorrentes, quanto pelo longo tempo em que o paciente fica sob os cuidados da equipe.

Algumas assertivas evidenciam esta visão mais ampla, contemplando um assistir holístico e humanizado: [...] cuidar é ir lá, ficar, conversar, participar, uma palavra de carinho, brincar [falou em tom baixinho], isso também fazparte do cuidar, na oncologia, principalmente na oncologia (E azul). [...] eu tento me dedicar a eles, dar atenção, me interessar pelo que eles estão falando, ter um bom relacionamento com o acompanhante, brincar, conversar, você cria um vinculo muito forte com esses pacientes (E branca).

Percebe-se, portanto, que o aspecto emocional está muito presente na assistência ao paciente oncológico, devendo a enfermeira proporcionar uma assistência que privilegie o humano, ao atender o cliente holisticamente.

No decorrer do processo terapêutico, a enfermagem é a categoria que tem possibilidade de maior tempo de contato com a clientela. Suas ações não se restringem aos procedimentos meramente técnicos. A este proceder, devem se aliar e serem contempladas as diversas características concernentes ao humano deste ser, privilegiando assim, os aspectos sócio-psico-espirituais. É o que se percebe nos depoimentos: [...] você tem uma ligação muito forte com, com os pacientes, tem ligação emocional, eles dependem muito de você (E branca). [...] A gente procura dar um apoio emocional pro paciente. Procurar estar sempre próximo dele (E amarela).

Vale ressaltar, que a família do cliente com câncer merece apoio e cuidados especiais por parte dos enfermeiros, pois é ela que dá o suporte para enfrentar as diferentes crises da vida, as rupturas emocionais, conflitos, exigências bem como afirmar, proteger e definir padrões de comportamento, valores e crenças. ${ }^{11}$

A família, principalmente aquela a que pertence um paciente com câncer, pode apresentar sentimentos de medo, culpa, depressão e raiva, devendo a enfermeira também a ela, direcionar suas atenções. As profissionais devem estar atentas, conhecer e reconhecer este vivenciar, agindo em função de suas necessidades que podem ser, dentre outras, de esperança, informação e apoio.

Neste sentido, a enfermeira deve se preocupar com a qualidade de vida do paciente, não poupando esforços para diminuir seu sofrimento, como também de seus familiares. ${ }^{12}$ 
Esse lado emocional com relação à família é bem exemplificado através das seguintes falas: [...] eu tento estar próxima desse paciente o máximo que eu posso e dessa família (E rosa). [...] ter integração com a família... (E marrom).

O cuidado é essencial a todos os clientes, independente do seu quadro clínico, mas essa ligação emocional enfermeira - paciente - família é observada com maior freqüência com relação a pacientes sem condições de um bom resultado terapêutico, o que acontece com freqüência na especialidade oncológica.

Apesar de se ter a possibilidade de cura para muitos clientes com neoplasias malignas, as enfermeiras, em várias oportunidades, associam o quadro desta clientela, à terminalidade, o que as pode levar ao desenvolvimento de sentimentos de angústia, sofrimento e impotência.

A morte é um fato consumado, mas ao mesmo tempo inaceitável para o ser humano, pois vivemos como se nunca fossemos morrer, e talvez seja por isso, que as profissionais de enfermagem, apesar de discussões sobre morte e morrer, não estão preparados para atender no processo de morte. ${ }^{13}$

Muitas vezes, no cotidiano da prática oncológica, as profissionais se deparam com a morte de um paciente sob seus cuidados e enfrentam sentimentos que muito as mobiliza: [...] a gente não trabalba bem essa questão da perda, infelizmente a gente sabe, que, paciente oncológico, a gente sabe, que infelizmente, muitas vezes o final não é muito feliz, (E rosa).

Há uma negação à morte, pois esta não é vista como um acontecimento natural e sim como causador de frustração, sensação de fragilidade, medo e impotência. Esses sentimentos tornam-se exacerbados, pois apesar do papel da enfermeira não ser salvar vidas, buscando, basicamente, a cura do outro, desejamos sempre o bem-estar do paciente. Essas profissionais, por vezes, supervalorizam habilidades técnicas afastando de seu agir, a possibilidade de morte, o que pode ocasionar perda de uma relação interpessoal mais autêntica e fortalecedora entre a enfermeira e o cliente. ${ }^{10}$

A associação entre doença - terminalidade - sensação de impotência intrínseca, é expressa em alguns relatos: [...] como a maioria das pessoas sabe muitas vezes o câncer, ele não tem cura [...] (E amarela). [...] você se sente um pouco sem ação, você é impotente, sempre na frente da morte, que a gente depara com ela todo dia [emocionou-se] (E verde).
O paciente portador de câncer pode ter medo $\mathrm{da}$ morte, associando a doença à morte iminente, tornando-se profundamente ansioso e vivenciando agudo sofrimento. Cabe à enfermeira, demonstrar carinho, calor humano, compaixão, ouvindo-o, tocando-o suavemente e ficando ao seu lado. Muitas vezes, ele apenas precisa saber que tem ali alguém ao seu lado, que o conhece, se importa e pode compreendê-lo e, sobretudo, que não o deixará passar sozinho, por este momento que lhe parece tão difícil.

A fé, muitas vezes, ajuda a este cliente, família e profissionais, a caminharem por uma estrada que apesar de não ser tão iluminada, terá mais brilho e será mais fácil de percorrer, com este suporte. É importante sonhar, comparar a luz no fim do túnel com a qualidade de vida possível, com o poder caminhar, respirar, suspirar e viver, sempre vivendo da melhor forma e transcedendo os próprios limites existenciais. ${ }^{2}$ Neste sentido, aponta este depoimento: [...] é acreditar, acreditar na esperança, na fé, senão você não consegue trabalhar. A fé em Deus, em um Deus, é Deus que vem primeiro e te dá a mão pra gente conseguir trabalhar, porque senão você pira (E verde).

O cuidado humano - espiritual é essencial para a assistência de enfermagem completa, ele perpassa toda a assistência, quando passa a sentir com o paciente, passa a olhar com os olhos da fé e acreditar na transcendência. Pessoas significativas que têm sua individualidade apreciada e estimulada, são seres completos que necessitam viver em harmonia com Deus, consigo mesmo e com o próximo. ${ }^{10}$

No cotidiano da prática, a enfermeira desenvolve ações que objetivam, especialmente, proporcionar a recuperação do completo bem estar da clientela sob seus cuidados. Seu agir então, visa à manutenção e/ou a recuperação da saúde. Ao dispensar cuidados a um paciente que não tem mais possibilidades de cura, deve-se ter em mente que este cuidar tem em sua essência propiciar a melhor qualidade de vida, no tempo de vida que ele tenha.

\section{A sistematização da assistência: uma estra- tégia de aplicação do conhecimento no coti- diano do cuidar}

O conhecimento e a experiência, também são estratégias muito utilizadas pela enfermagem para o alcance de uma assistência de qualidade. $\mathrm{O}$ saber originado no cotidiano da prática associado ao suporte teórico sinaliza a necessidade de resolução das limitações, propiciando um cuidado, melhor 
fundamentado. A busca do aprendizado, do autoconhecimento e da interação com a equipe multiprofissional, são fatores que poderão vir a contribuir essencialmente neste processo.

A ansiedade, os medos, as inseguranças, as incertezas, a impotência e o peso da tarefa a ser desempenhada, produzem desconforto nas enfermeiras e nas pessoas cuidadas. Por isso, a importância e necessidade das profissionais, aprimorarem seus conhecimentos e habilidades específicas para poder, com segurança e eficiência, cuidar dos portadores de câncer e sua família. ${ }^{14}$

A busca pelo conhecimento e aprimoramento, é evidenciada em alguns depoimentos: [... buscando mesmo atualização, de tratamento, de parte científica de estar lendo sobre oncologia, como é que é a dor, como é que é a medicação, e como que faz, como que acontece na quimioterapia, como é que é a radio, como que acontece a leucemia, o que a gente vai fazer, como é que vai lidar com o cateter (E branca).

[...] se aperfeiçoar, tecnicamente e cientificamente o má ximo que possivel, estar procurando se informar sobre a doença, procurando participar de simpósio, de congresso, sair conversando com outros profissionais (E lilás).

[...] ir aprimorando todo o servico, melhorando toda parte desde o atendimento com os pacientes, a educação com os funcionários (E vermelha).

O conhecimento serve de base e suporte para a enfermeira que cuida, pois ao técnico e ao teórico, se aliam a cientificidade do fazer profissional gerando o cuidado. A satisfação profissional pode ser alcançada através da segurança alicerçada e fundamentada no conhecimento, levando as profissionais a se sentirem confiantes em suas ações, ao serem capazes de identificar corretamente os problemas do paciente sob seus cuidados.

Apesar da relevância de utilização da SAE para o cuidado de qualidade, as falas das profissionais de ambas as instituições, apontam um agir que não é contemplado, na maioria das vezes, por uma atuação assistencial sistematizada. No cotidiano do cuidar, há referências a um agir que, embora demonstre ter esta fundamentação, não ocorre de forma metodologicamente intencional.

Ressalta-se que embora as depoentes façam referências a sistematização da assistência como estratégia de aplicação do conhecimento, esta não se configura em sua prática. Destacam-se, em algumas oportunidades, ações que, embora sejam realizadas em consonância com algumas etapas do processo, não são adequadamente registradas: [...] a gente vai trabalhando de acordo com a necessidade do paciente, a gente não faz muito as coisas por escrito, muitas vezes é verbal. A metodologia por escrito, fazer aquele diagnóstico, fazer uma prescrição de enfermagem, isso na prática a gente não realiza (E amarela).

[...] a gente tem a metodologia que a gente já tem na cabeça, a gente já levanta o diagnóstico, mas é tudo muito na hora, passei, olhei há uma orientação da equipe, mas a nivel de papel não (E laranja).

As profissionais alegam como fatores dificultadores intervenientes para este agir assistemático, o número elevado de pacientes e a pequena quantidade de enfermeiros nas instituições pesquisadas: [...] porque são poucos enfermeiros, a realidade nossa, acho que aqui no Brasil são muitos poucos enfermeiros (E laranja).

[...] pouco funcionário, um monte de coisa que atrapalha implementar o trabalho (E vermelha).

[...] por enquanto não dá, porque são muitos pacientes, e pra fazer supervisão não tem como, é um enfermeiro só pra vários paciente (E marrom).

A SAE e seu registro no prontuário do cliente é uma característica da enfermagem moderna, representando uma conquista para os profissionais e para os pacientes, refletindo, quando não implementada, na perda das ações das enfermeiras no tempo e no espaço e dificultando a interação com a equipe multidisciplinar e, conseqüentemente, afetando a qualidade da assistência prestada ao paciente oncológico.

A inserção e implementação desta prática, $d a$ forma preconizada, além de refletir em um processo do cuidar qualitativamente melhor, contribuem efetivamente com seus registros documentais, para o suporte ético e legal das ações destas profissionais.

\section{CONSIDERAÇÕES FINAIS}

Embora já se tenha um grande avanço tecnológico em seu diagnóstico e tratamento, o câncer ainda se encontra vinculado à idéia de terminalidade, acarretando nas enfermeiras sentimentos de angústia, sofrimento e impotência diante da morte. A análise dos depoimentos deste estudo demonstrou, contudo, que esse pode ser o caminho para a realização de um cuidado holístico e humanizado ao paciente portador de câncer e sua família. Tendo-se como estratégia a utilização da SAE, há a possibilidade de ser gerado maior interesse de se atualizar cientificamente e tecnologicamente, refletindo na qualidade da assistência prestada.

Cuidar de pacientes portadores de câncer, apesar de causar algum sofrimento, poderá produzir um 
sentimento de gratificação nas profissionais. Um simples toque, um gesto de carinho pode ajudar o cliente a valorizar, dentro de suas possibilidades, pequenas ações que poderão levar o mesmo a sorrir, a seguir em frente, e principalmente, propiciar bem estar e melhor qualidade, ao tempo de vida que ele tiver.

Os depoimentos evidenciaram vivências do cotidiano profissional perpassadas por características essencialmente femininas na relação estabelecida com a clientela, tanto no que se refere à implementação do cuidado, quanto no retorno derivado deste vivido.

A análise das entrevistas demonstrou a presença de um cuidar holístico e humanizado, o sofrimento e a sensação de impotência das enfermeiras diante da morte, a presença da fé como suporte de seu agir e o interesse em atualizar-se cientificamente e tecnologicamente, porém aponta inconsistências na implementação da SAE.

\section{REFERÊNCIAS}

1 Souza ML, Sartor VVB, Padilha MICS, Prado ML. O cuidado em enfermagem-uma aproximação teórica. Texto Contexto Enferm. 2005 Abr-Jun; 14 (2): 266-70.

2 Ferreira SS, Neves EP. Ser enfermeira vivenciando o cuidado ao cliente com câncer em tratamento quimioterápico. RECENF: rev. técnico-científ. enferm. 2003 Jan-Fev; 1 (1): 49-54.

3 Beghini AB, Salimena AMO, Melo MCS, Souza IEO. Adesão das acadêmicas de enfermagem à prevenção do câncer ginecológico: da teoria à prática. Texto Contexto Enferm. 2006 Out-Dez; 15 (4): 637-44.
4 Minayo MCS. Pesquisa social: teoria, método e criatividade. Petrópolis (RJ): Vozes; 1994.

5 Ministério da Saúde (BR), Conselho Nacional de Saúde, Comissão Nacional de Ética em Pesquisa. Resolução No 196 de 10 de outubro de 1996: diretrizes e normas regulamentadoras de pesquisa envolvendo seres humanos. Brasília (DF): MS; 1996.

6 Martins J, Bicudo MAV. A pesquisa qualitativa em psicologia: fundamentos e recursos básicos. São Paulo (SP): Morais; 1989.

7 Boff L. Ética e moral a busca dos fundamentos. Petrópolis (RJ): Ed. Vozes; 2003.

8 Costenaro RGS, Lacerda MR. Quem cuida de quem cuida? Quem cuida do cuidador? Santa Maria (RS): Centro Universitário Franciscano; 2002.

9 Furegato,ARF. Relações interpessoais terapêuticas na enfermagem. Ribeirão Preto (SP): Scala,1999.

10 Costenaro RGS. Cuidando em enfermagem: pesquisas e reflexões. Santa Maria (RS): Centro Universitário Franciscano; 2001.

11 Zanchetta MS. Enfermagem em cancerologia: prioridades e objetivos assistenciais. Rio de Janeiro (RJ): Revinter; 1993.

12 Baracat FF, Fernandes JR, Jadir H, Silva MJ. Cancerologia atual: um enfoque multidisciplinar. São Paulo (SP): Roca; 2000.

13 Fischer ES, Silva MJP. Reações emocionais da enfermeira no atendimento ao paciente fora de possibilidades terapêuticas. Rev. Nursing. 2003 Nov; 66 (6): 25-30.

14 Arruda EM, Marcelino SR. Cuidando e confortando. In: Schulze CMN. Dimensões da dor no câncer: reflexões sobre o cuidado interdisciplinar e um novo paradigma da saúde. São Paulo (SP): Robe Editorial; 1997. p. 157-89. 